\title{
DISCUSSION ABOUT THE EFFECT OF DIGITAL PLANTS LIBRARY ON THE PLANTS LANDSCAPE RESTORATION IN YUANMINGYUAN
}

\author{
Liang Binga, ${ }^{\mathrm{a},}$, Song Guxin ${ }^{\mathrm{a}}$, Li Gongli ${ }^{\mathrm{b}}$ \\ a'Beijing Re-Yuanmingyuan Company Limited.100085Beijing, China-(liangbing, songguxin)@thid.cn \\ bBeijing Qingda Transsim Technologies, Inc.100085Beijing, China-ligongli@thid.cn
}

KEY WORDS: Digital, Plants Library, Yuanmingyuan, Plants Landscape, Three-dimensional Model, Original Feature Research

\begin{abstract}
:
Chinese classical garden emphasizes not only the construction of building, mountains and rivers, spring and stone landscape but also the selection and configuration mode of the plant species. Yuanmingyuan, a classical work of Chinese garden art, is of both the magnificence of northern royal garden and the delicacy of southern private garden. The plants landscape in Yuanmingyuan also has its own unique style. But it is regretful that after several disasters, it nearly disappears just as other building clusters. The ReYuanmingyuan group re-presents the plants landscape of Yuanmingyuan through investigation, restoration and three-dimensional space generation, and makes proposal about the concept of digital plants library for the first time with the expectation to provide basic support for the digital restoration of cultural heritage by establishing the plants library. The paper also introduces the process of digital plants library system construction as well as the significance of the library construction for the landscape restoration in Yuanmingyuan and even the northern royal garden.
\end{abstract}

\footnotetext{
* Corresponding author
} 


\section{INTRODUCTION}

The previous studies tend to limit their attention to garden or Yuanmingyuan alone instead of setting Yuanmingyuan into the royal garden system or historical background of Qing Dynasty or cultural communication between China and the west. They ignore the objective fact that garden is born in certain historical and cultural system, which causes the lack of historic and stereoscopic sense.

The Florence Charter mentions that historical garden is mainly composed of plants. So, it has vital force, both living and dead. Its feature reflects the seasonal circulation, natural transition and garden art. Yuanmingyuan is the most prestigious "Garden of Gardens" among Chinese royal gardens for its magnificence of northern royal garden and delicacy of southern private garden. Anglo-French Allied Force opened the door to this royal garden with gunfire in 1860, which declared the start of its declination. After the destruction including fire, wooden, stone and earth robbery, the buildings and garden landscape in it are beyond recognition now. Therefore, in order to re-present the dreamy landscape as well as the architectural space in this palace, the Re-Yuanmingyuan group has started the building and landscape restoration study and design, digital model construction, and three-dimensional digital scene fabrication since 2009. They have also carried out the plants landscape research, restoration design and three-dimensional scene re-presentation at the same time. After nearly 5-year plants landscape restoration design study and three-dimensional spatial fabrication, the research group has basically sorted out the directory of the major plants in Yuanmingyuan, and established the corresponding CAD map depot and three-dimensional plant model library.

Plants simulation remains as a hot spot in the study of computer graphics, while shape modeling is a key step in the plants simulation. The difficulty lies in the fact that plants are especially irregular with strong structural features, diversified figures and complicated shape. The models in the plants model library have wide application base in the world, but they still appear to be deficient for the scene restoration in Yuanmingyuan. The major causes include: (1) the plants in the plants model library are mainly woody, and the species are limited; (2) majority of plants in Yuanmingyuan are from Northern China while the plants in the plants model library are mainly from Southern China and even oversea countries, so the models can not be directly used; (3) the model library emphasizes the overall vividness of the three-dimensional model without taking into consideration the true ecological shape of the models and lacking corresponding data support.

\section{SIGNIFICANCE OF DIGITAL PLANTS LIBRARY FOR YUANMINGYUAN}

\subsection{Necessity of establishing digital plants library}

Re-Yuanmingyuan is a large-scale and long-term project. How to display the plants landscape in the scene remains as a puzzling problem. The three-dimensional plants seem phony and can not achieve the restoration effect with high precision when being few, and increase the file and data quantity and affect the scene operating speed when being excessive. We have being long devoted to finding how to reasonably employ the present technology to improve the effect of three-dimensional plants. The existing plants production software and related plants libraries are not directly available after being downloaded, for some of them are to serve the film, television and game, and some of them are to be applied to the design sketch of garden landscape or plant species study. On the basis of the requirement for restoring virtual scene authenticity, it is really important to create an independent and specific plants library.

\subsection{Provide convenience for plants landscape restoration in Yuanmingyuan}

On the basis of previous studies about historical plants in Yuanmingyuan, carrying out profound research about the plants materials in the scenic spots restoration design of which has been completed, as well as sort out and summarize the major plants materials in the scenic spots. Meanwhile, through an analysis of the general background conditions of Western Suburb of Beijing in Qing Dynasty (including natural conditions and plantation conditions), we gradually sort out a relatively complete Yuanmingyuan plants material library, including plants photo library, plants CAD photo depot, threedimensional plants model library, plus illustrations as the basis for the subsequent scenic spot restoration design.

\subsection{Make the restored scene more authentic}

The employment of computer in the garden plants model library establishment further deepens the landscape study. The plants model is an important constituent part of the three-dimensional landscape model. No matter used in the computer graphic exhibition or virtual reality, the garden plants landscape is critical, for it can directly affect the authenticity and natural atmosphere of the scene.

The Venice Charter makes proposal about the principles of "authenticity" and "completeness" in respect of cultural heritage protection. In order to reveal the plants landscape of Yuanmingyuan in different historical periods in a more authentic way, the research group had been to the existing royal gardens and arboretums for many times, so as to take photos as materials in accordance with the plants landscape characteristics of Yuanmingyuan, including the trunks, twigs and leaves of different plants in the same season as well as the same plants in different seasons. The use of authentic tree materials in the three-dimensional scene to produce the plants landscape model of authentic effect breaks the limitation of traditional plane study and succeeds in re-presenting the authentic garden space, so that the public can feel being in the real garden and appreciate the transition of scenes from different perspectives and dimensions.

\section{ESTABLISHMENT OF DIGITAL PLANTS LIBRARY FOR YUANMINGYUAN}

\subsection{Principles for the establishment of digital plants library}

The principle for the establishment of Yuanmingyuan plants library is to realize the plants cultivation with high precision and reflect the plants landscape as authentic as possible. To generate natural and authentic virtual scene requires reasonable modeling which means use of the data volume as less as possible in controlling the virtual objects, so as to harvest relatively satisfactory effect in the vividness and controllability. In order to realize the ideal effect, besides definite plants species and position as reference, we need also a plants library that has high precision and natural and authentic effect as support.

\subsection{Investigation into the plant material species}

The plant species investigation is the premise and basis for the restoration design and plants directory establishment. We firstly 
re-sort out the Value of Flowers and Trees recorded in the Rules for the Work in Yuanmingyuan. In accordance with the statistical results, there are altogether over 80 kinds of plants which can serve as the first hand and fundamental materials for Yuanmingyuan Plants Library. Then we combine such drawings and archives as forty scenes (Figure 1), Yangshifang Drawings (Figure 2) and Royal Poetry to estimate the plant species in the scenic spots and draft characteristic plant directory of the scenic spots. In addition, as the prospect, spatial functions and features expressed by different scenic spots as well as the features of the royal garden construction in Qing Dynasty, we choose some plant species that grow in Beijing at that time to be added into the plants directory.

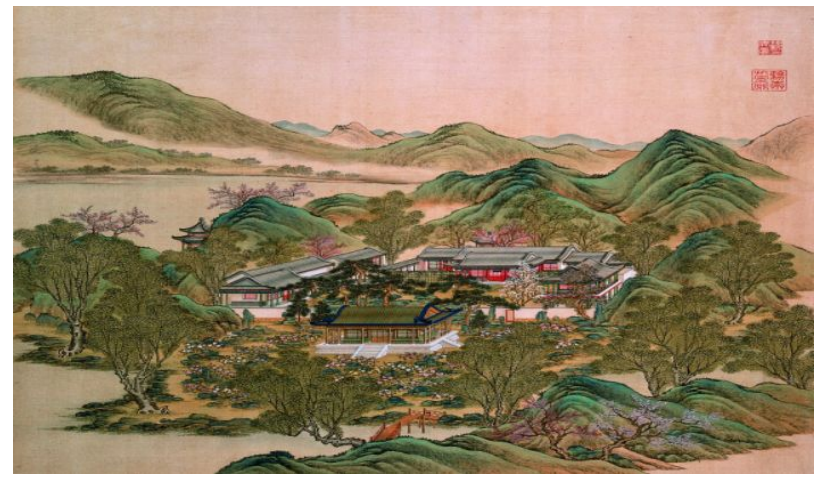

Figure 1. Forty scenes of the Yuanmingyuan of the Scenic Area of Louyuekaiyun

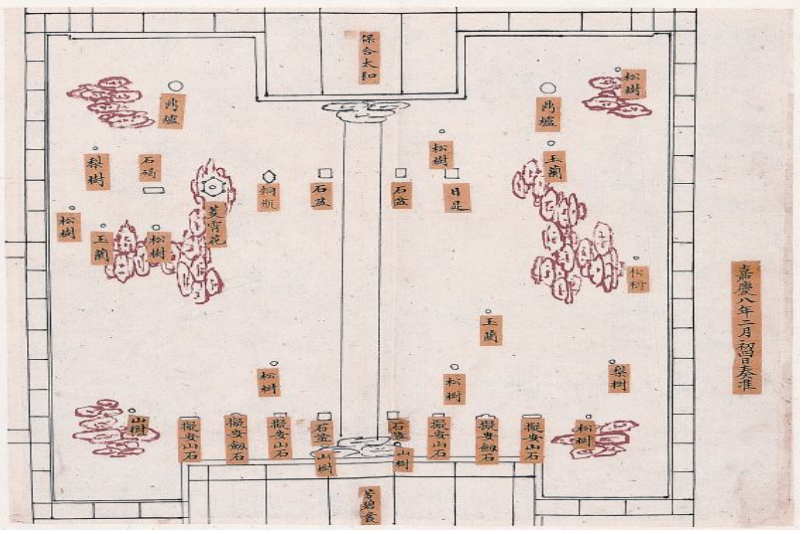

Figure 2. Qinzhengqinxian Yangshifang Drawing

\subsection{Plant materials collection and arrangement}

The trees have extremely complicated properties. The present visual tree model generally focuses on the aboveground parts, such as trunk, twig and leaves. So, we collect the information about the aboveground visual parts of the trees. It is not so difficult to measure the trees. The primary thing is to set up the tree measurement data collection plan or determine which kind of data should be collected. The measurement of trees' morphology and size can be achieved by traditional surveying and mapping practitioners, referring to the book Forest Measuration (Figure 3), through specific instruments and methods of surveying and mapping. What should be measured includes the tree height, crown diameter, diameter at breast height, the trunk, branches, leaves, etc (Table 1).

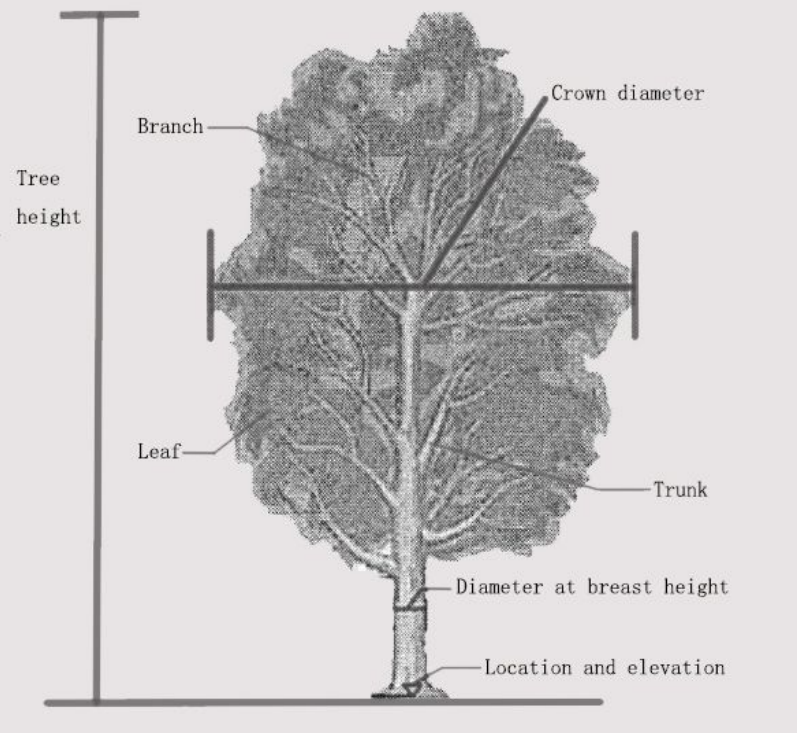

Figure 3. Trees Measurement Standard

Measuring instruments used arevernier caliper, range pole, tape measures, meter rulers and cameras.

Measuring methods: (1)Measurements of the tree trunk, including the quantity, height and angel of trunks. In this process, trunk radius at the four directions were measured, then chose the average value as the final data. (2)Measurements of tree branches, including the quantity, length and angel of branches. (3)Measurements of tree leaves, including the quantity, length and leaf area of leaves. When undertaking this measurement, 20 leaves of a tree were randomly selected to measure the size, length, width and other dimensions.

\begin{tabular}{|c|c|c|c|c|c|}
\hline Part & \multicolumn{5}{|c|}{ Basic data } \\
\hline Trunk & $\begin{array}{c}\text { Quanti } \\
\text { ty }\end{array}$ & height & angle & Radius & Map \\
\hline Branch & $\begin{array}{c}\text { Quanti } \\
\text { ty }\end{array}$ & length & $\begin{array}{c}\text { Angle } \\
\text { betwe } \\
\text { en } \\
\text { branch } \\
\text { and } \\
\text { main } \\
\text { branch }\end{array}$ & Radius & Map \\
\hline Leaf & $\begin{array}{c}\text { Quanti } \\
\text { ty }\end{array}$ & length & $\begin{array}{c}\text { Propor } \\
\text { tion of } \\
\text { leaves } \\
\text { in the } \\
\text { whole } \\
\text { tree }\end{array}$ & Size & Map \\
\hline
\end{tabular}

Table 1. Collection of basic data about plants

\subsection{Three-dimensional plants model fabrication and application}

3.4.1 Three-dimensional model fabrication. The research team drafts the plants restoration demand table as the scenic spot functions, seasonal aspects and plants usage frequency (Table 2). The project adopts the plants of virtual reality scenes and there are three ways of realization: permanent-surface single-leaf plant, manual-surface plant and three-dimensional plant. (1) Permanent-surface single-leaf plant: in the Autodesk 3ds Max, 
the whole tree is completed with one surface. The surface can keep facing the operator after receiving corresponding command (Figure 4). In this way, the file volume is low, the fabrication is simple, and the authentic effect is good. Nevertheless it is improper for the expression of large trees, such as Salix babylonica beveling into the river, or the densely cultivated trees which can produce overlapping image and affect the landscape effect of the whole scene. (2) Manual-surface plant: the whole plant adopts two or above surfaces expressed in the form of crossing. The file volume is low and the fabrication is simple, but the authentic effect is far from being satisfactory, and the controllability is poor (Figure 5). (3) Three-dimensional plant: it means the major branches of the trees are solid models while the twigs and leaves are expressed with surface (Figure 6) As for this approach, the file volume is high, while the landscape effect is more superiorer than the first two methods.

The primary goal of designing $3 \mathrm{D}$ plant model is to use the smallest data capacity to present the most vivid and real effect created by plants. The basic data about the colors and geometric shapes of plants are mainly acquired by referring to plants in reality and by using the methods mentioned above.

\begin{tabular}{|c|c|c|c|}
\hline Plant Name & Type & $\begin{array}{c}\text { Seasonal } \\
\text { Aspect }\end{array}$ & $\begin{array}{c}\text { Landscape } \\
\text { Usage } \\
\text { Frequency }\end{array}$ \\
\hline $\begin{array}{c}\text { Armeniaca } \\
\text { sibirica }\end{array}$ & $\begin{array}{c}\text { Small } \\
\text { trees }\end{array}$ & Spring scenery & 5 \\
\hline Morus alba & $\begin{array}{c}\text { Small } \\
\text { trees }\end{array}$ & Spring scenery & 4 \\
\hline $\begin{array}{c}\text { Rosa } \\
\text { chinensis }\end{array}$ & Shrubs & Spring scenery & 3 \\
\hline
\end{tabular}

Table 2. Demand about the fabrication of some plants in the library

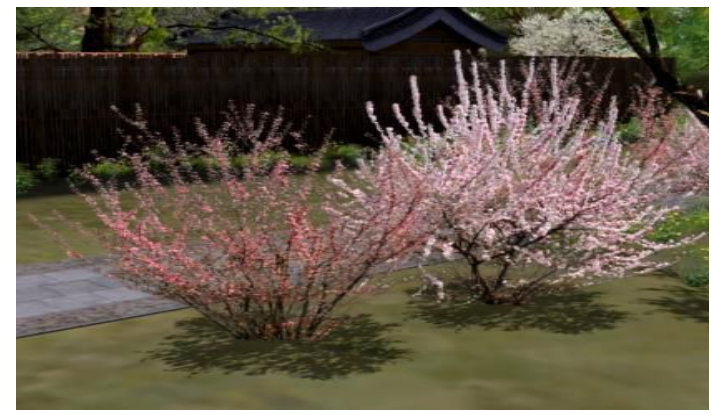

Figure 4. Permanent-surface Single-leaf Plant

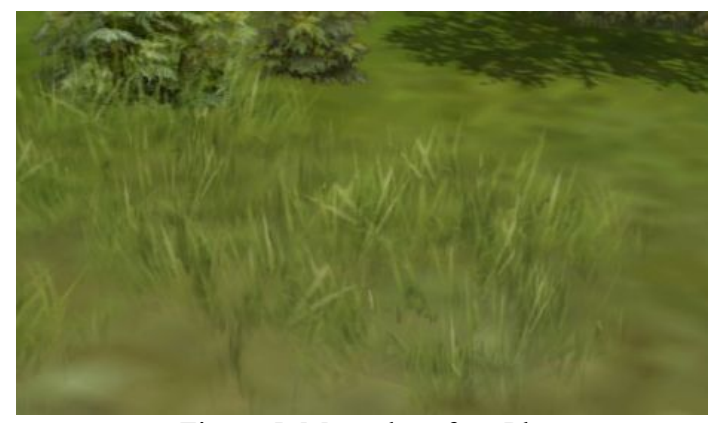

Figure 5. Manual-surface Plant

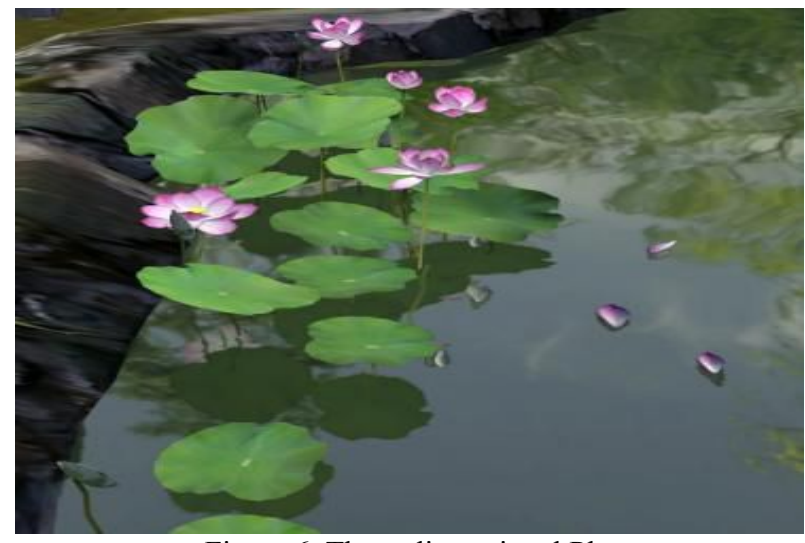

Figure 6. Three-dimensional Plant

At present, in the third phase of Re-Yuanmingyuan project, most of the plants adopt the first approach. There are models of about 176 kinds of plants and over 700 trees. For instance, as for the maidenhair tree there are 15 models, covering that in the spring, summer and autumn (Figure 7). In the key parts, there are plant models of about 30 kinds of plants and over 60 trees fabricated in the third approach. For example, as for bamboo, there are several types of three-dimensional groups which can be combined with the permanent-surface trees to display the target effect in the scene (Figure 8). Some of the plants adopt the second approach in the modeling as onsite environment, such as the herbaceous flowers. Altogether tens of such models have been fabricated. In general situation, several fundamental types are fabricated as the demand for the distant view. The models of heteromorphic trees, vines and climbing plants, such as the Wisteria sinensis on framework, will be made alone according to the terrain environment (Figure 9).

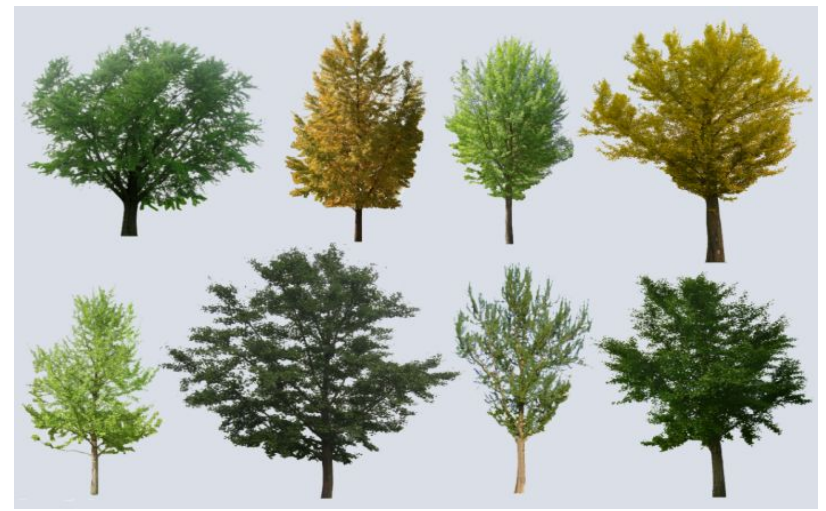

Figure 7. Ginkgo biloba of different postures and different seasonal aspects

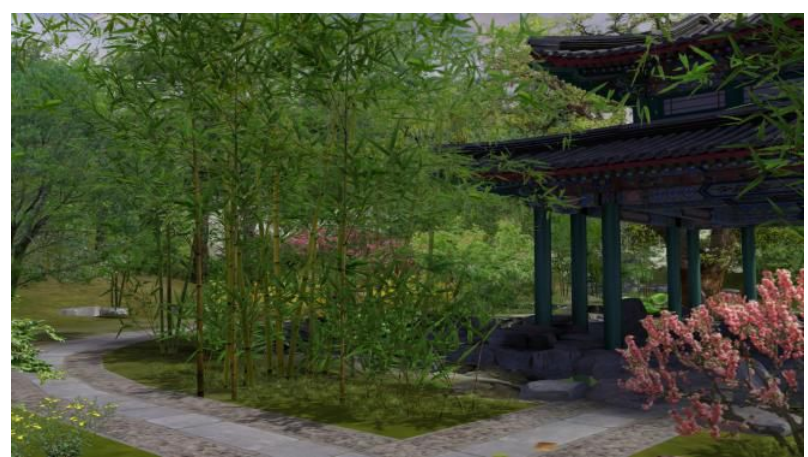

Figure 8. Bamboo in Three-dimensional Scene 


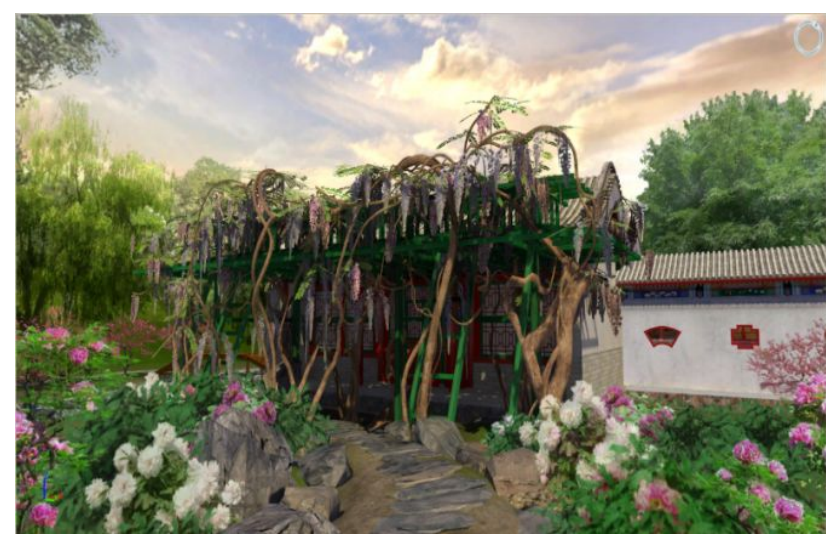

Figure 9. Wisteria in Three-dimensional Scene

3.4.2 The application of three-dimensional models of plants library in the scene. After obtaining the information about the plant position in the plants restoration design drawing, we choose proper plants from the plants library for matched plantation as the terrain environment. When all the plants are cultivated, it is still necessary to optimize and adjust the landscape effect of the scene plants, which requires high controllability of the plant materials. The adjustment of the plant height, size, shape and position can avoid the blocking on the building. It is also applicable to make use of the perspective, view borrowing, and crown canopy changing to improve the scene effect (Figure 10. Figure 11).

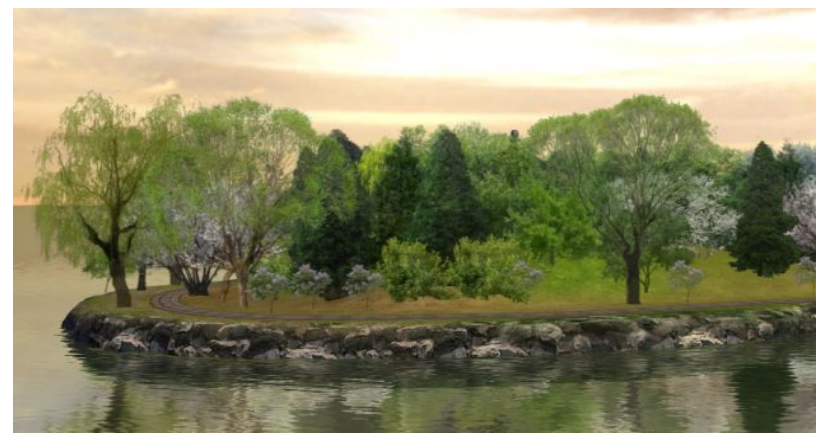

Figure 10. Plants scene before the adjustment

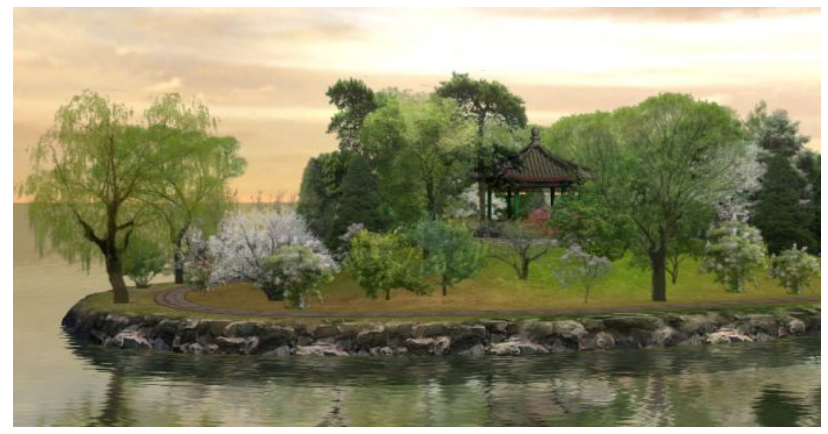

Figure 11.Plants scene after the adjustment

In order to improve the efficiency, availability and expandability of the plants in the scene, the Re-Yuanmingyuan research group also enhances the fabrication of threedimensional plants, and makes use of new plants fabrication software to produce more plant libraries that can better blend with the digital scene (Figure 12).

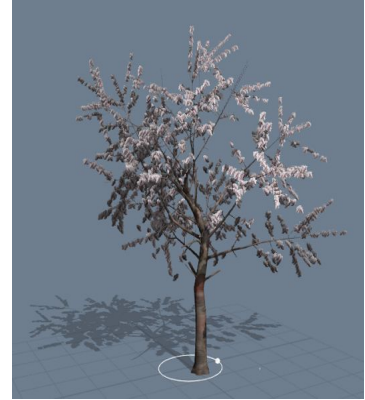

(a)

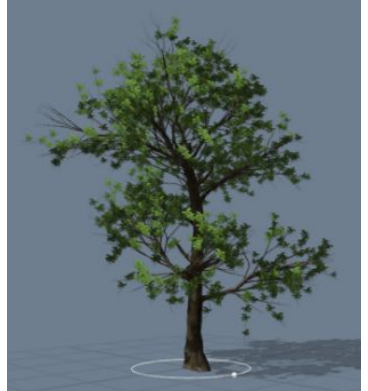

(b)
Figure 12. Effect Display of Plant Models

Now the group only tries in producing about 20 kinds of frequently used trees due to the unfamiliarity with the software application. The effect is not so ideal, but the utilizability is high. The most obvious strength of the new software is the possibility of producing more tree shapes after the fabrication of one tree and the easy realization of trees in different seasons. When it is necessary to display the deciduous trees in winter, the leaves hierarchy can be closed and exported again; and when it is to display the plants in autumn, it is required to change the leave color only. In addition, the tree species can be easily adjusted in the scene.

\section{CONCLUSION AND DISCUSSION}

The most fundamental objective of the plants landscape restoration study is to ensure the later plants landscape effect can be in accordance with the original historical appearance as much as possible. The Re-Yuanmingyuan research group combines large number of fundamental study materials and restoration study achievements, makes proposal about the concept of digital plant library system, and sets up CAD plant map depot and three-dimensional plant model library in order to provide basic support for the subsequent plants landscape restoration in Yuanmingyuan. It is also of great significance for the digital study about cultural heritage.

Although the digital plants library has harvested certain research achievements and has been applied to the landscape restoration of plants in Yuanmingyuan, it can be further improved and perfected. For instance, (1) Improve the measurement plan by making use of more advanced three-dimensional digital measurement tools and devices to obtain the needed data more accurately and rapidly; (2) Keep updating the plants species, types and ways of expression in different seasonal aspects in the plants library.

\section{REFERENCES}

Raymond Lemaire, Herb Stovel: Nara Document on Authenticity, Japan, 1994.

International Charter for the Conservation and Restoration of Monuments and Sites, Venice, 1964.

Rules for the Work in Yuanmingyuan[M]. Yuanmingyuan Digital Archives. Guo Daiheng Studio.

Jun Zhao. Study about the plants landscape in the prime of Yuanmingyuan[D]. Beijing Forestry University, May 2009.

Xiangyan $\mathrm{Wu}$. Study about the mountain-river and plants landscape protection in the prime of Yuanmingyuan[D]. Tsinghua University, July 2004. 
Xiangyan Wu, Guxin Song and Yue Liu. Illustration of Yuanmingyuan plants landscape restoration[M]. Shanghai Far East Publishers, December 2014.

Zhiyong Bai. SpeedTree-based plum blossom visual model construction[D]. Beijing Forestry University, September 2011.

Hao Yang. Category-based plants rapid generation in threedimensional scene[D]. Shanghai Jiaotong University, July 2008.

Li Yu. Study about the plants landscape and configuration way in the prime of Yuanmingyuan[J]. Science and Technology Office, Yuanmingyuan Management Agency.

Sheng Lu. Initial exploration about the garden plants threedimensional modeling approach $[\mathrm{J}]$. Journal of Beijing University of Agriculture, July 2004.

Yumei Wang, Chuangang Hao and Xiaofeng Jiang. Modeling of three-dimensional plants in natural scene $[\mathrm{J}]$. Journal of Suzhou University, April 2009. 